Int. J. Electrochem. Sci., 15 (2020) 3283 - 3297

\title{
Corrosion Inhibition Effect of Expired Ampicillin and Flucloxacillin Drugs for Mild Steel in Aqueous Acidic Medium
}

\author{
M. Alfakeer ${ }^{1}$, M. Abdallah ${ }^{2,3}$, A. Fawzy $y^{2,4, *}$ \\ ${ }^{1}$ Chemistry Department, Faculty of Science, Princess Nourah bint Abdulrahman University, Riyadh, \\ Saudi Arabia \\ ${ }^{2}$ Chemistry Department, Faculty of Applied Science, Umm Al-Qura University, Makkah, Saudi \\ Arabia \\ ${ }^{3}$ Chemistry Department, Faculty of Science, Benha University, Benha, Egypt \\ ${ }^{4}$ Chemistry Department, Faculty of Science, Assiut University, Assiut, Egypt \\ *E-mail: $\underline{\text { afsaad13@yahoo.com }}$
}

doi: $10.20964 / 2020.04 .09$

Received: 11 December 2019 / Accepted: 27 January 2020 / Published: 10 March 2020

The inhibition efficiencies of ampicillin and flucloxacillin expired drugs on mild steel (MS) corrosion in $1.0 \mathrm{M}$ sulfuric acid medium was examined at $20^{\circ} \mathrm{C}$ using weight loss (WL), and electrochemical potentiodynamic polarization (PDP) and electrochemical impedance spectroscopy (EIS) techniques. Examined expired drugs are set to be efficient inhibitors for MS corrosion in sulfuric acid medium. The experimental outcomes of weight loss technique displayed that the inhibition performances of the investigated expired drugs augmented with increasing concentrations of such drugs and reduced by raising the temperature. The observed high inhibition efficiencies of the studied expired drugs may be owing to powerful adsorption of the drug species on MS surface resulting in formation of protective layers. Adsorption of the tested expired drugs on the MS surface was set to accord with Langmuir adsorption isotherm. The assessed thermodynamic parameters supported the mechanism of physical adsorption of the inhibitors.

Keywords: Expired drugs, Inhibitors, Corrosion, Mild steel, Adsorption.

\section{$\underline{\text { FULL TEXT }}$}

(C) 2020 The Authors. Published by ESG (www.electrochemsci.org). This article is an open access article distributed under the terms and conditions of the Creative Commons Attribution license (http://creativecommons.org/licenses/by/4.0/). 